\title{
Microstructure and Mechanical Properties of Stainless Steel Component Manufactured by Shaped Metal Deposition
}

\author{
Tomas SKIBA, ${ }^{1,2)}$ Bernd BAUFELD ${ }^{11}$ and Omer van der BIEST ${ }^{11}$ \\ 1) MTM, Katholieke Universiteit Leuven, Kasteelpark Arenberg 44, 3001 Leuven, Belgium. \\ 2) Department of Materials, FNSPE, Czech Technical University in Prague, Trojanova 13, 12000 Prague 2, Czech Republic. \\ E-mail: bernd.baufeld@mtm.kuleuven.be
}

(Received on February 2, 2009; accepted on June 5, 2009)

\begin{abstract}
A novel near net-shape layer-by-layer welding technique-Shaped Metal Deposition (SMD)—using Tungsten Inert Gas (TIG) welding was employed to produce components from a 308 stainless steel wire. This technique is meant to fabricate metal components for rapid prototyping or for reparation of components when no additional tooling is available. The mechanical properties of components prepared by this novel route have to be known before application, since they do not necessarily coincide with the properties of components derived from conventional fabrication methods.

The component exhibits a microstructure composed of austenite and vermicular $\delta$ ferrite with the predominance of austenite. Neither the structure nor the mechanical properties are dependent on the height of the component. The mechanical properties are comparable to those of components prepared by conventional techniques.
\end{abstract}

KEY WORDS: shaped metal deposition; microstructure; mechanical properties; welding; stainless steel.

\section{Introduction}

Shaped Metal Deposition (SMD) is a promising near netshape technique for additive layer manufacturing of components. This technique is especially applicable for rapid prototyping of metal components or for reparation of parts in situations where no additional tooling is available (e.g. in space applications). SMD consists of continuous, layer-bylayer deposition applying conventional tungsten inert gas (TIG) welding in an Argon atmosphere (Fig. 1).

Besides SMD, ${ }^{1-4)}$ other techniques such as direct laser fabrication $^{5-14)}$ and electron beam freeform fabrication ${ }^{15-17)}$ are also studied for additive layer manufacturing. The subject of most of these investigations are Ti alloys; exceptions are the studies on the Ni base alloy IN718, ${ }^{2}$ on the ultra high-strength low alloy steel $300 \mathrm{M},{ }^{4}$ and on the aluminum alloy $2219 .{ }^{15)}$

In the present case, type 308 austenitic stainless steel is investigated for the first time for the application of SMD. The aim is to obtain steel components with high corrosion resistance and high ductility. The excellent weldability predestinates this material to be applied for this task. In cast condition the microstructure of 308 steel is predominantly austenitic, while in welds a combination of austenite and ferrite can be found. ${ }^{18)}$ The amount of ferrite depends strongly on the cooling rates, ${ }^{19)}$ with higher cooling rates implying a higher volume fraction of ferrite (up to $30 \%$ ). ${ }^{20}$ ) The typical morphology of ferrite in 308 stainless steel weldments is vermicular. ${ }^{20-22)}$ The material may also contain precipitates of $\mathrm{M}_{23} \mathrm{C}_{6}$ type carbides along the austenite- ferrite boundaries and tiny $\sigma$ phase precipitates in ferrite. ${ }^{21,23)}$ The morphology of ferrite in stainless steels is dependent on the solidification process. 308 stainless steel is expected to solidify in the ferritic mode, which means that $\delta$ ferrite is the first solid phase formed from liquid. ${ }^{24-27)}$

As SMD consists of continuous layer-by-layer welding, special attention has to be paid to material sensitization. The sensitization is the precipitation of chromium carbides at the grain boundaries of heat affected zones (HAZ) resulting into formation of surrounded chromium depleted zones. $^{28,29)}$ These zones are responsible for severe degradation of corrosion resistance and also of tensile properties (especially ductility). Since SMD provides components formed exclusively of HAZ, possible degradation of mechanical properties (compared to cast component) has to be

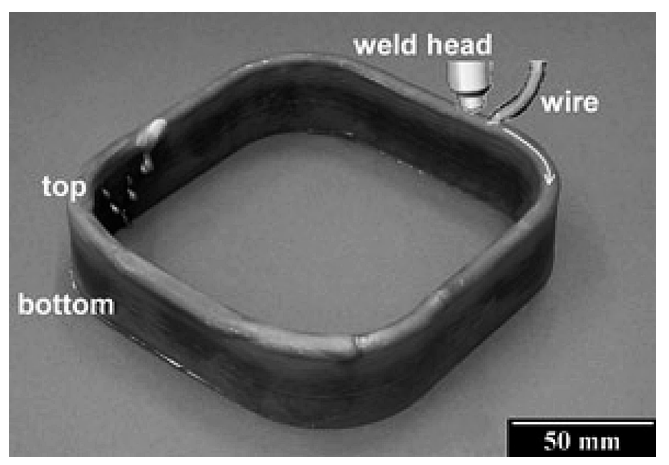

Fig. 1. Schematic of the SMD process of a 308 stainless steel component in the form of a low tube with a rectangular base. 
taken into account.

Due to the anisotropic fabrication route, additive layer manufacturing may lead to inhomogeneous structures and to a dependence of mechanical properties on the location and orientation within the component. The prospective designer of a component needs to know the mechanical properties and their relation with location and orientation. Well established properties of materials fabricated by conventional techniques or of single welds can not necessarily be used, since this special fabrication route includes multiple welds, which lead to sequential heat treatments, and may result in new microstructures and unknown properties. The aim of the present paper is therefore to report for the first time the microstructure and mechanical properties of a 308 austenitic stainless steel component fabricated by SMD.

\section{Experimental}

The SMD was performed at Advanced Manufacturing Research Centre at the University of Sheffield, UK using a tungsten inert gas welding head attached to a Kuka robot which is linked to a two-axis table. Welding head, robot, and table are enclosed in an airtight chamber ensuring an inert gas atmosphere which consists of Argon controlled to $99.999 \%$ purity. More details about the set-up can be found elsewhere. ${ }^{3)}$ The material used was 308S93 stainless steel (supplier Rodacciai) and the base plate mild steel. The final component, a tube with a rectangular base of approximately $130 \times 130 \mathrm{~mm}$ (see Fig. 1), was build up layer by layer by 30 welding steps and exhibits a height of $31 \mathrm{~mm}$. The wall thickness is about $8 \mathrm{~mm}$. The welding parameters such as wire feed speed, electric current and speed of the table were $2000 \mathrm{~mm} \cdot \mathrm{min}^{-1}, 160 \mathrm{~A}$ and $0.25 \mathrm{~m} \cdot \mathrm{min}^{-1}$, respectively.

The microstructure was studied by means of optical (OM) and scanning electron microscopy (SEM) using a Leitz and a Philips FEG XL 30 microscope, respectively. Cross sections were prepared, grinded and polished by standard means, and electrolytically etched for $20 \mathrm{~s}$ at $12 \mathrm{~V}$ in oxalic acid.

Vickers microhardness tests (using Leitz equipment) were performed with a load of $100 \mathrm{~g}$. More than 300 indents were applied on cross sections of the component with different orientations and on different heights.

Horizontally oriented tensile specimens were prepared from locations approximately 11 to $27 \mathrm{~mm}$ from the base plate. The specimens, having a dog bone shape, exhibit a gauge length of $10 \mathrm{~mm}$ and a cross-section of $2 \times 3 \mathrm{~mm}^{2}$. Tests were carried out using an Instron machine with a displacement rate of $0.5 \mathrm{~mm} \cdot \mathrm{min}^{-1}$.

The impulse excitation technique ${ }^{30)}$ (IMCE, Diepenbeek, Belgium) was used for measurements of elastic modulus on horizontally oriented specimens taken from the bottom part of the component. The dimensions of the specimens were approximately $3 \times 7 \times 25 \mathrm{~mm}^{3}$.

Room temperature XRD measurements were realized with a Siemens D500 equipment.

\section{Results}

SMD was successfully applied to fabricate a 308 stainless steel component (Fig. 1). Figure 2 presents a cross-

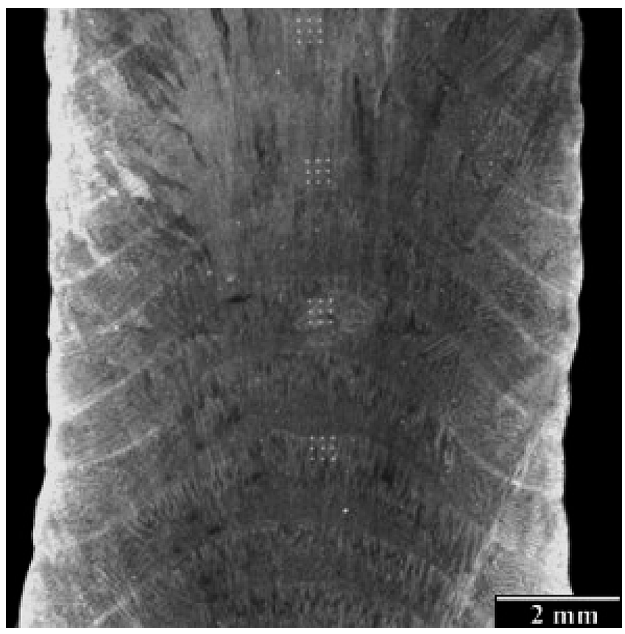

Fig. 2. OM; cross section of the middle part of the component, $\Omega$ banded structure related to the deposition layers; groups of $3 \times 3$ indents from hardness measurements located in the middle of the wall.

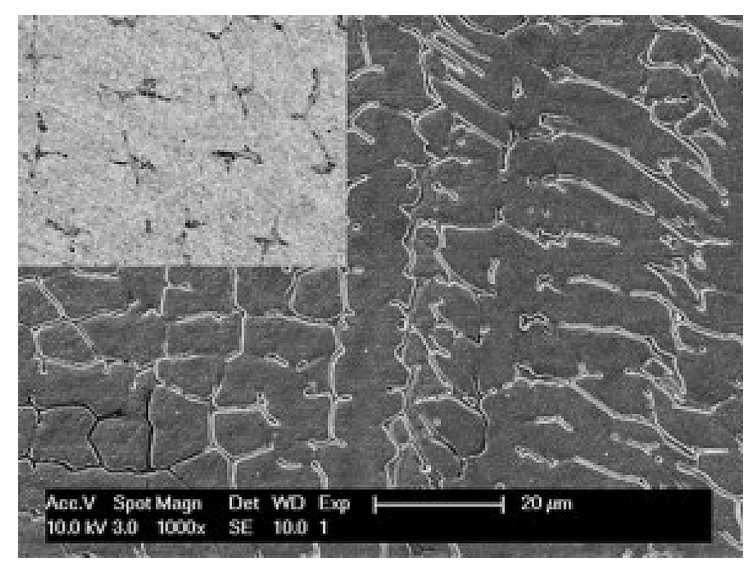

Fig. 3. SEM; middle part of the component, viewed perpendicular to the deposition direction; the inset shows similar structures viewed parallel to the deposition using back scattered electrons.

section, viewed in direction of the table movement. It is possible to distinguish ' $\Omega$ ' shaped bands which correspond to the deposition layers. The boundaries between the bands are very sharp towards the wall sides but become misty in the middle part of the component. In detailed inspections, elongated grains were discerned, which are oriented vertically in the middle, but bending towards the wall surfaces near the edges.

The microstructure of the component consists mainly of austenite and ferrite (Fig. 3). Carbides and $\sigma$ phase precipitates as observed in literature ${ }^{21)}$ can not be proven with the techniques applied. Throughout the component, ferrite appears mostly in form of vermicular structures (Fig. 3), sometimes also referred to as dendritic coring. ${ }^{21)}$ These structures are oriented in vertical direction in the middle of the wall, while they are bended at both sides towards the wall surfaces. The inset in Fig. 3 shows similar structures observed for a cross section cut perpendicular to the deposition direction. Vermicular ferrite particles are then displayed as stars, typically up to $10 \mu \mathrm{m}$ in diameter. The very top area (within $200 \mu \mathrm{m}$ from the top) and the side surface areas are characterized by randomly oriented structures 
(Fig. 4). These are called acicular or Widmanstätten austenite. $^{31,32)}$

Two phases are identified by XRD: $\gamma$ austenite and $\delta$ ferrite with the predominance of $\gamma$ austenite throughout the component. No apparent dependence of the relative amount on height is observed. The measurements reveal a considerable texture. The lattice parameters are determined to be 0.359 and $0.288 \mathrm{~nm}$ for $\gamma$ austenite and $\delta$ ferrite, respectively. The literature values for $\gamma$ and $\delta$ are reported as 0.3589 and $0.2882 \mathrm{~nm}^{33,34)}$

Extensive microhardness tests over the whole cross section of the component do not reveal any dependence of the microhardness on height or orientation of the sample. The overall microhardness is $186+/-15 \mathrm{HVM}_{100}$. The results from tensile tests are summarized in Fig. 5. No significant dependence of the ultimate tensile strength (UTS) or $0.2 \%$ yield strength (YS) on the height is observed. The average value is 537 and $312 \mathrm{MPa}$ for UTS and YS, respectively. However, a certain dependence on the height of the SMD component seems to exist for the ductility. A very high average ductility of $59 \%$ and more is measured. The specimens situated near the top of the component reveal lower values than the specimens located in the bottom. The average value of the elastic modulus is $159 \pm 4 \mathrm{GPa}$.

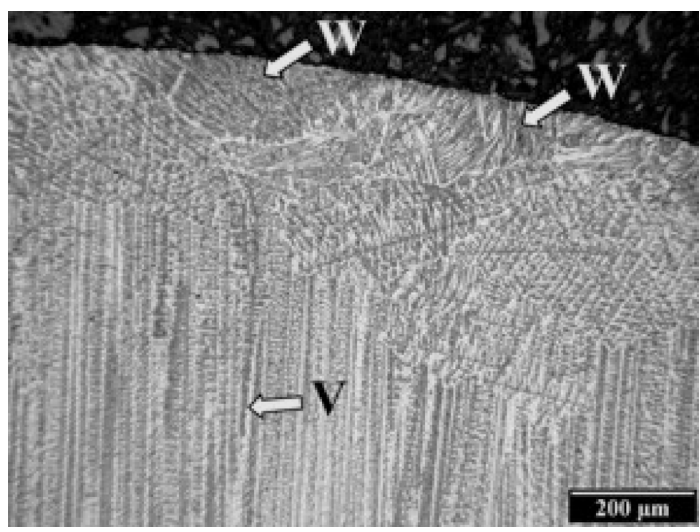

Fig. 4. OM; top part; vertically oriented vermicular ferrite (denoted as V) and areas of Widmanstätten austenite (W).

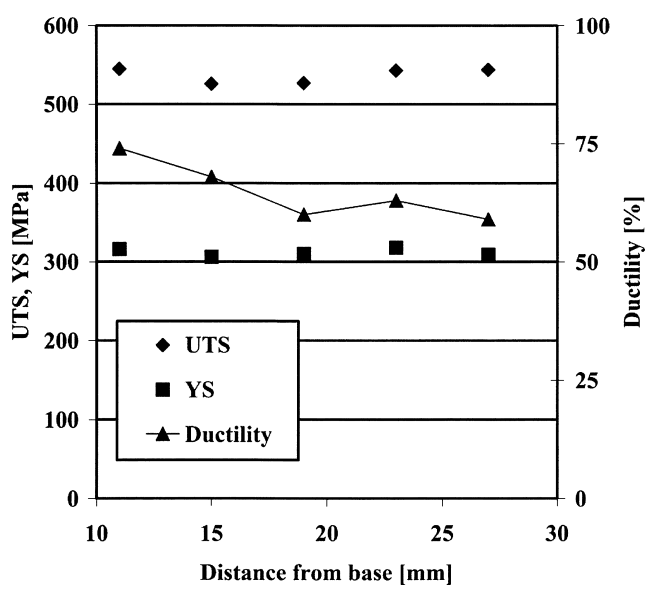

Fig. 5. Tensile tests results of specimens taken from areas from 11 to $27 \mathrm{~mm}$ above the base plate with tensile direction perpendicular to the SMD deposition direction: ultimate tensile strength (UTS), $0.2 \%$ yield strength (YS), and ductility.

\section{Discussion}

Using the Schaeffler diagram ${ }^{27,35)}$ a ferrite volume ratio slightly below $10 \%$ is expected for 308 stainless steel. According to the $\mathrm{Cr}_{\mathrm{eq}}: \mathrm{Ni}_{\mathrm{eq}}$ ratio (about 1.9), $\delta$ ferrite forms first from the liquid phase. ${ }^{25,27)}$ During further cooling, below $1400^{\circ} \mathrm{C}$, remains of liquid as well as $\delta$ ferrite, which was formed last and exhibits a somewhat lower amount of $\mathrm{Cr}$, start to transform into austenite, leaving the amount of ferrite at a level below $10 \%$. The vermicular ferrite is a remnant of $\delta$ ferrite dendrites growing in the direction of the thermal gradient. Therefore vermicular ferrite possesses the same direction as the dendrites. While there is a continuous vertical temperature gradient in the middle of the component wall leading to parallel vermicular ferrite, the additional surface cooling is responsible for irregular, interconnected structures.

The tensile tests show values comparable to that of material prepared by conventional techniques. The UTS of SMD specimens of $537 \mathrm{MPa}$ is within the range, which is between 515 and $620 \mathrm{MPa}$, depending on the exact condition of preparation. ${ }^{18)}$ The YS of $312 \mathrm{MPa}$ is even higher than the values given for cast material $\left(200-300 \mathrm{MPa}^{1)}\right)$. The ductility of more than $60 \%$ is higher than that of conventionally prepared specimens $\left(30-40 \%{ }^{18)}\right.$ ) and welds (up to $45 \%)^{20)}$ This indicates that the TIG SMD 308 stainless steel component do not suffer from considerable $\mathrm{M}_{23} \mathrm{C}_{6}$ type chromium carbide formation accompanied by reduction of ductility. A slight decrease of the ductility with the height could be attributed to the fact that the bottom part experienced somewhat longer annealing leading to the reduction of residual stresses or slight change in morphology. Yet, based on present data, the variation of the elongation can be also just an experimental error.

\section{Conclusions}

Components made out of 308 stainless steel can be fabricated by SMD, promising the application of this additive layer manufacturing technique for rapid prototyping of metal components with high corrosion resistance and high ductility. Present results can be summarized as follows:

(1) Component is composed of predominantly of $\gamma$ austenite and $\delta$ ferrite. The $\delta$ ferrite appears in form of vermicular structures which are denser near the top of the component as well as close to the wall surfaces. Close to the top surface of the component some regions of Widmanstätten austenite exist.

(2) Component exhibits practically no anisotropy of mechanical properties with the height or orientation.

(3) The mechanical properties are comparable to that of components prepared by conventional methods. No degradation of the mechanical properties due to possible sensitization was observed. Therefore, with TIG SMD a rapid prototyping technique is given to fabricate stainless steel components with good mechanical properties.

\section{Acknowledgements}

Acknowledgement goes to the RAPOLAC STREP project (contract no. 030953) of the 6th Framework Programme of the European Commission (www.RAPOLAC.eu), to the 
Advanced Manufacturing Research Centre, UK, and to the research fund of $\mathrm{K}$. U. Leuven in the framework of the Flanders-Czech bilateral project BIL/05/56.

\section{REFERENCES}

1) M. Katou, J. Oh, Y. Miyamoto, K. Matsuura and M. Kudoh: Mater. Des., 28 (2007), 2093.

2) D. Clark, M. R. Bache and M. T. Whittaker: J. Mater. Process. Technol., 203 (2008), 439.

4) T. Skiba, B. Baufeld and O. van der Biest: JISR Int., (2009), accepted.

5) P. A. Kobryn and S. L. Semiatin: Mechanical Properties of LaserDeposited Ti-6Al-4V Solid Freeform Fabrication (Austin, Tx, USA, 2001), ed. by D. L. Bourell, J. J. Beaman, R. H. Crawford, H. L. Marcus, L. Wood and J. W. Barlow, The University of Texas at Austin, (2001).

6) X. Wu and J. Mei: J. Mater. Process. Technol., 135 (2003), 266.

7) X. Wu, R. Sharman, J. Mei and W. Voice: Mater. Des., 25 (2004), 103.

8) F. Wang, J. Mei and X. Wu: Appl. Surf. Sci., 253 (2008), 1924.

9) L. Qian, J. Mei, J. Liang and X. Wu: Mater. Sci. Technol., 21 (2005), 597.

10) S. Nowotny, S. Scharek, E. Beyer and K.-H. Richter: J. Therm. Spray Tech., 16 (2007), 344.

11) F. Wang, J. Mei, H. Jiang and X. Wu: Mater. Sci. Eng. A, 445-446 (2007), 461.

12) S. H. Mok, G. Bi, J. Folkes and I. Pashby: Surf. Coat. Technol., 202 (2008), 3933

13) S. H. Mok, G. Bi, J. Folkes, I. Pashby and J. Segal: Surf. Coat. Technol., 202 (2008), 4613.

14) E. Brandl, C. Leyens, F. Palm, A. Schoberth and P. Onteniente: Eurou. Rapid (Berlin, Germany) (2008),

15) M. S. Domack, K. M. Taminger and M. Begley: Mater. Sci. Forum, 519-521 (2006), 1291.

16) K. M. Taminger and R. A. Hafley: Proc. of NATO/RTOAVT-139 Specialists' Meeting on Cost Effective Manufacture via Net Shape
Processing, NATO, Amsterdam, the Netherlands, (2006), 9.

17) Arcam 2008 www.arcam.com (2008.12.01)

18) S. D. Washko and G. Agger: Wrought Stainless Steels. ASM Metals Handbook, 10th ed., Ohio: ASM International Handbook Committee, (1990), 841.

19) V. Muthupandi, P. B. Srinivasan, S. K. Seshadri and S. Sundaresan: Mater. Sci. Eng. A, 358 (2003), 9.

20) J. M. Vitek, S. A. David, D. J. Alexander, J. R. Keiser and R. K. Nanstad: Acta Metall. Mater., 39 (1991), 503.

21) S. Babu, S. David, J. Vitek and M. Miller: Appl. Surf. Sci., 87-8 (1995), 207.

22) R. F. Mehl: Microstructures of Wrought Stainless Steels. In: Committee AIH, editor. ASM Metals Handbook. Ohio: ASM International, (1972), 131.

23) A. F. Padilha and P. R. Rios: ISIJ Int., 42 (2002), 325.

24) R. Kacar: Mater. Des., 25 (2004), 1.

25) T. A. Siewert, C. N. McCowan and D. L. Olson: Weld. J., 67 (1988), S289.

26) S. H. Kim, H. K. Moon, T. Kang and C. S. Lee: Mater. Sci. Eng. A, 356 (2003), 390.

27) I. Woo and Y. Kikuchi: ISIJ Int., 42 (2002), 1334.

28) K. Nishimoto, H. Mori and Y. Nakao: ISIJ Int., 35 (1995), 1265.

29) P. K. Ghosh and Vivek: ISIJ Int., 43 (2003), 85.

30) G. Roebben, B. Bollen, A. Brebels, J. van Humbeeck and O. van der Biest: Rev. Sci. Instrum., 68 (1997), 4511.

31) J. A. Brodes and J. C. Lippold: Selection of Wrought Austenitic Stainless Steels. In: Committee AIH, editor. ASM Metals Handbook, Vol. 6: Welding Brazing, and Soldering, ASM International, Ohio, (1993), 456

32) H. D. Solomon and T. M. Devine: Duplex Stainless Steels, ed. by R. A. Lula, ASM International, Ohio, (1983), 693.

33) D. J. Dyson and B. Holmes: J. Iron Steel Inst., 208 (1970), 469.

34) J. M. Leitnaker and T. N. Kingston: Delta ferrite-containing austenitic stainless steel resistant to the formation of undesirable phases upon aging, US patent no. 4265983 (1981).

35) H. B. Cary: Modern Welding Technology, Prenice-Hall Inc., New Jersey, (1979), 736. 